\title{
Disinfection of woollen blankets in steam at subatmospheric pressure
}

\author{
V. G. ALDER AND W. A. GILlESPIE \\ From the Department of Pathology, Bristol Royal Infirmary
}

SYNOPSIS Blankets may be disinfected in steam at subatmospheric pressures by temperatures below boiling point inside a suitably adapted autoclave chamber.

The chamber and its contents are thoroughly evacuated of air so as to allow rapid heat penetration, and steam is admitted to a pressure of $10 \mathrm{in}$. $\mathrm{Hg}$ below atmospheric pressure, which corresponds to a temperature of $89^{\circ} \mathrm{C}$. Woollen blankets treated 50 times by this process were undamaged. Vegetative organisms were destroyed but not spores.

The method is suitable for large-scale disinfection of blankets and for disinfecting various other articles which would be damaged at higher temperatures.

The regular disinfection of bedclothes is now being undertaken in many hospitals in order to reduce the risks of cross-infection. In the Bristol Royal Infirmary, the present practice is to disinfect all bedding (including bedcovers and dressing gowns as well as blankets and sheets) once a fortnight, or when the patient leaves hospital.

Non-woollen goods are adequately disinfected by laundering in hot water but woollen blankets present a special problem. While they may be disinfected satisfactorily by laundering with quaternary ammonium compounds (Blowers and Wallace, 1955) or in hot water at a slightly acid $p \mathrm{H}$ (Dickinson, Wagg, and Fairchild, 1959), pressure of work and lack of space in the laundry of this hospital make it difficult to treat the large number of blankets required (approximately 250 per day). The same problem would exist with non-woollen blankets. For this reason a vacuum formaldehyde process has been used routinely for the past four years (Gillespie and Alder, 1957; Caplan, 1959). Investigation of the temperature in the chamber revealed that the blankets on the outside of the load were raised to temperatures of between $90^{\circ}$ and $95^{\circ} \mathrm{C}$. Despite this heating, no damage to the blankets was detected and this suggested that woollen blankets might be safely disinfected by steam at temperatures not much below $100^{\circ} \mathrm{C}$., if the steam could be made to penetrate through several thicknesses of blanket material. The recent development of high pre-vacuum autoclaves has made this practicable.

\section{PRINCIPLE}

The chamber and its contents are thoroughly evacuated of air so as to allow rapid penetration of steam into the load. Steam is admitted to a pressure of $10 \mathrm{in} . \mathrm{Hg}$ below atmospheric pressure, which corresponds to a temperature of $89^{\circ} \mathrm{C}$. (Fig. 1). The wall of the chamber is kept warm to prevent heat loss, and condensate is removed by steam traps capable of operating below atmospheric pressure.

\section{METHOD}

Most of the experiments were done with a Slater horizontal, jacketed, gravity-displacement autoclave, of 25

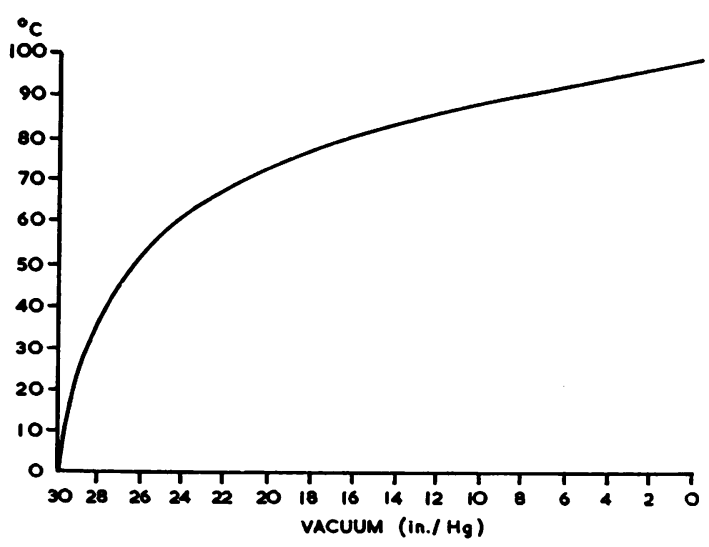

FIG. 1. Temperatures of saturated steam at low pressures. 


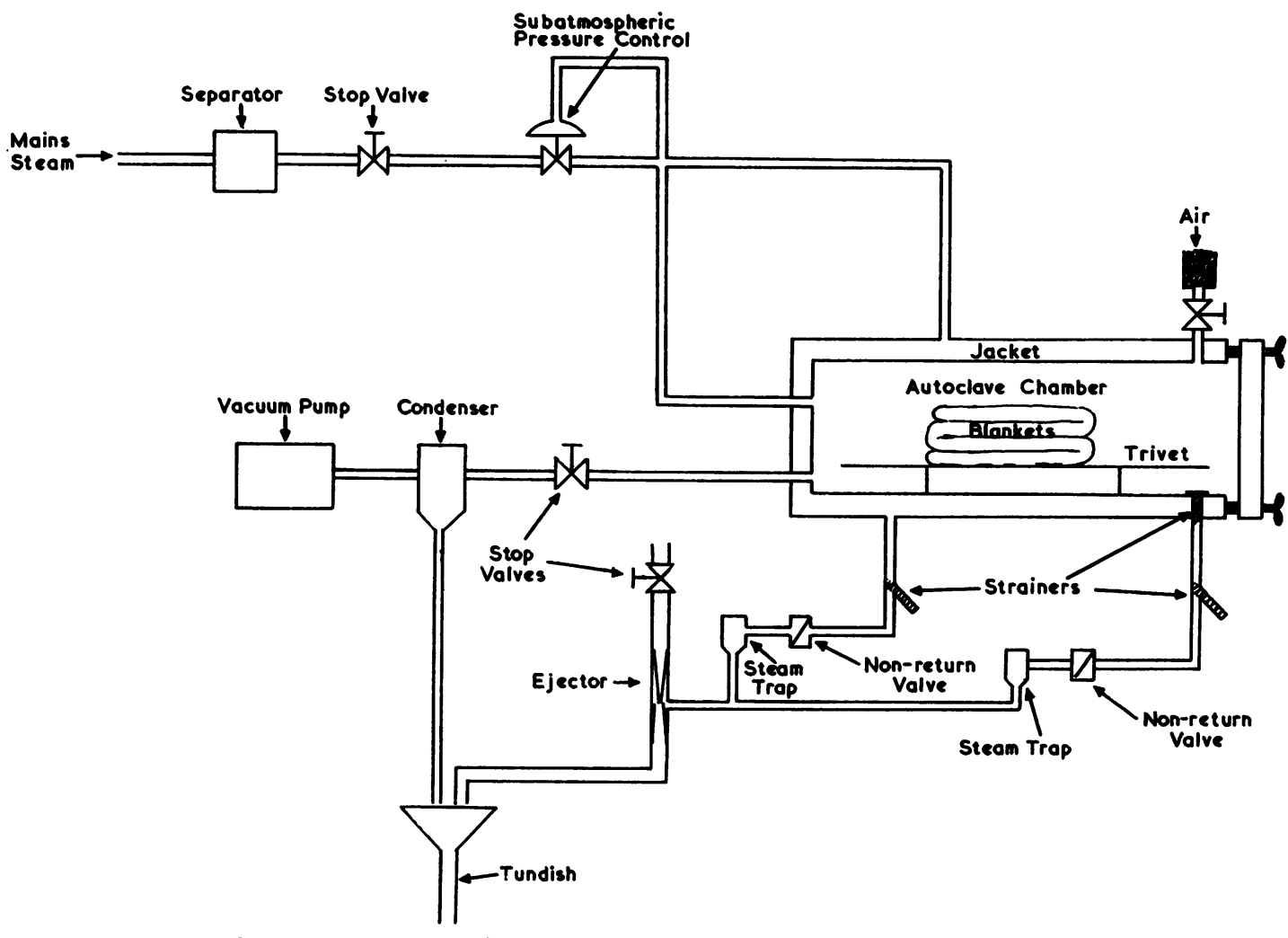

FIG. 2. Diagram of autoclave modified to work at subatmospheric pressures.

cubic foot capacity. The autoclave had been in use since 1949 , and was recently upgraded to 'high pre-vacuum status' by fitting an Edward's oil-sealed pump and condensing unit, and Drayton automatic controls (Alder and Gillespie, 1959). The piping arrangements are shown in Fig. 2. Two modifications were made so as to allow the autoclave to run at subatmospheric pressures: (1) A control valve fitted at the steam inlet was operated automatically by the pressure in the chamber. The valve could be adjusted to respond to pressures over a wide range, but in the present experiments (except when otherwise stated) it was set to close when the pressure reached minus 10 in. Hg. (2) A water ejector was fitted to the chamber and jacket drains in order to keep the pressure on the outlet side of the balanced pressure steam traps below minus 10 in. $\mathbf{~ H g}$. Without this modification the traps could not operate.

The standard process was operated as follows:

Blankets, folded once lengthwise, were stacked inside the chamber. Up to 30 hospital blankets could be accommodated in one load. The closed chamber was then evacuated down to minus 29.25 in. $\mathrm{Hg}(20 \mathrm{~mm}$. positive pressure), after which steam was admitted to the chamber. The disinfection period was timed from the moment when the temperature in the centre of the blanket pile reached $65^{\circ} \mathrm{C}$. A 30-minute period of disinfection was used in most of the experiments. At some time during this period, the chamber pressure reached minus $10 \mathrm{in}$. $\mathrm{Hg}$ and thereafter fluctuated by plus or minus $2 \mathrm{in} . \mathrm{Hg}$ as the automatic control valve opened and shut. After the disinfection period, the chamber was evacuated again to a pressure of minus $29 \mathrm{in}$. $\mathbf{H g}$. to dry the blankets. Filtered air was then admitted to the chamber, and the blankets removed.

A few experiments were done at higher temperatures.

Records of temperatures at various places inside the chamber and inside the load were obtained by means of thermistors (Alder and Gillespie, 1957) or mercury-insteel thermometers.

\section{RESULTS}

HEAT PENETRATION Many experiments were carried out to record changes in temperature at the centre and at the outside of loads of 25 to 30 blankets.

The temperature in the centre of the load, inside 50 thicknesses of blanket, rose promptly with the pressure but always lagged about $2^{\circ} \mathrm{C}$. below the ambient chamber temperature. Figure 3 shows the temperature and pressure recordings in a typical experiment. 


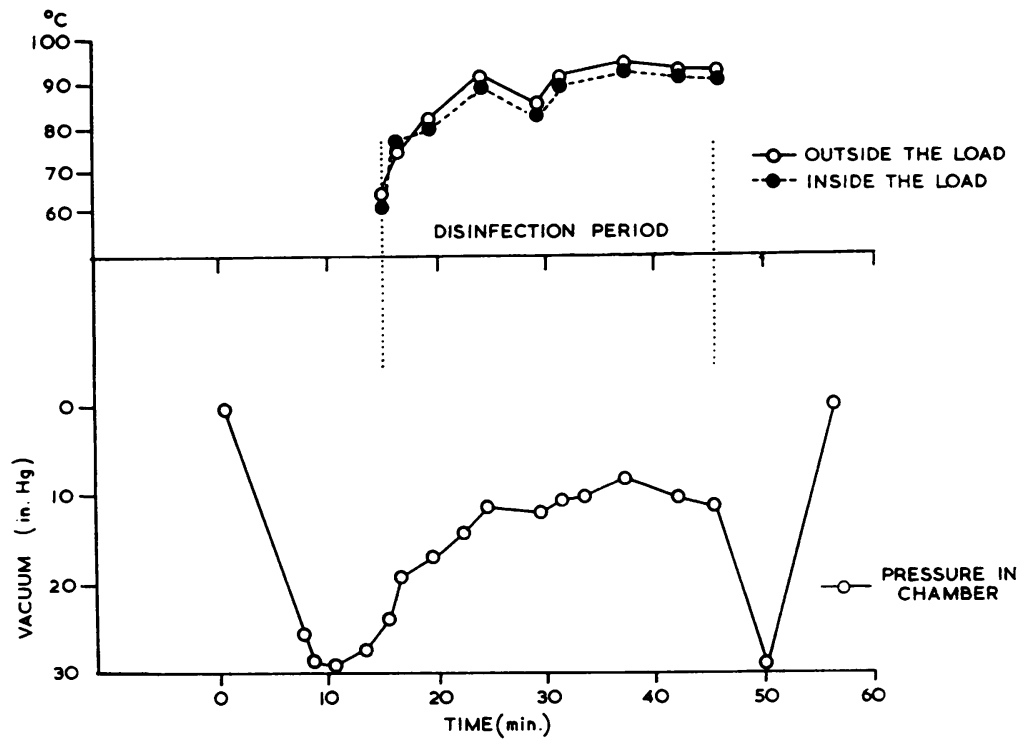

FIG. 3. Temperatures inside and outside a blanket load, in relation to steam pressure.

BACTERIOLOGICAL EFFECTS Sweep plate cultures taken from blankets before and after treatment by the method of Williams (cited by Blowers and Wallace, 1955) showed that vegetative organisms were consistently killed but that there was little destruction of sporing organisms.

The bacteriological efficiency of the method was also demonstrated by placing test organisms on dried paper discs enclosed in 2 in. $\times \frac{3}{8}$ in. test tubes plugged with cotton wool. The tubes were placed at various depths throughout the load. The test organisms were Staphylococcus aureus, Streptococcus faecalis, Eschericia coli, and Mycobacterium tuberculosis (H $37 \mathrm{RV})$. The test discs, together with unheated controls, were cultured in broth at $37^{\circ} \mathrm{C}$. for three days. Discs impregnated with tubercle bacilli were tested for sterility by culture for two weeks in Dubos liquid medium and by guinea-pig inoculation.

With a disinfection period of 30 minutes, the test organisms were killed, except on one occasion when tubercle bacilli and staphylococci survived at the bottom of a load of blankets. When the disinfection period was shortened to 20 minutes or less there were more survivals as shown, in the Table.

EFFECTS ON BLANKETS Since the physico-chemical effect of heat on wool partly depends on $p \mathrm{H}$, three identical new woollen blankets were sent to the Wool Industries Research Association where their reactions were adjusted to $p \mathrm{H} 4 \cdot 0,7 \cdot 0$, and $9 \cdot 8$ respectively. The blankets were then returned to Bristol and disinfected 50 times by the standard

TABLE

DISINFECTION OF TEST ORGANISMS INSIDE LOADS OF BLANKETS EXPOSED TO STEAM AT SUBATMOSPHERIC PRESSURES

\begin{tabular}{|c|c|c|c|c|c|c|c|c|c|c|c|}
\hline \multirow{3}{*}{$\begin{array}{l}\text { Duration of } \\
\text { Disinfection Period } \\
\text { (after temperature } \\
\text { reached } 65^{\circ} \mathrm{C} \text {.) }\end{array}$} & \multirow{3}{*}{$\begin{array}{l}\text { Final } \\
\text { Temperatures }\end{array}$} & \multicolumn{10}{|c|}{ Test Organisms } \\
\hline & & \multicolumn{2}{|c|}{ S. aureus } & \multicolumn{2}{|l|}{ B. coli } & \multicolumn{2}{|c|}{ Str. faecalis } & \multicolumn{2}{|c|}{ M. tuberculosis } & \multicolumn{2}{|c|}{ B. subtilis } \\
\hline & & Killed & Survived & Killed & Survived & Killed & Survived & Killed & Survived & Killed & Survived \\
\hline $\begin{array}{l}15 \text { minutes } \\
20 \text { minutes } \\
30 \text { minutes } \\
30 \text { minutes }\end{array}$ & $\begin{array}{l}80^{\circ}-83^{\circ} \mathrm{C} \text {. } \\
80^{\circ}-85^{\circ} \mathrm{C} \text {. } \\
86^{\circ}-90^{\circ} \mathrm{C} \\
100^{\circ} \mathrm{C}\end{array}$ & $\begin{array}{l}10 \\
12 \\
89 \\
14\end{array}$ & $\begin{array}{l}3 \\
1 \\
1 \\
0\end{array}$ & $\begin{array}{r}-3 \\
3 \\
\end{array}$ & $\begin{array}{r}-1 \\
0 \\
-\end{array}$ & $\frac{5}{55}$ & $\frac{1}{0}$ & $\frac{-}{12}$ & $\overline{1}^{1}$ & $\frac{\overline{0}}{14}$ & $\frac{\overline{9}}{0}$ \\
\hline
\end{tabular}

'A pair of tests at the bottom of a pile of blankets in one experiment (See text) 
process. Strips of material were removed after 25 and 50 treatments and sent back to the Association, which reported that at the end of 25 treatments there was no noticeable deterioration in the physical and chemical properties of the blanket, and the wearing properties did not appear to be impaired. After $\mathbf{5 0}$ treatments the Association again reported that there was virtually no change in the strength of the blankets and changes in the chemical constants were not appreciable.

\section{DISCUSSION}

The advantages of the subatmospheric steam method are speed and cheapness. After treatment the blankets are dry. In some recent experiments it has been found possible to disinfect approximately 75 blankets per hour, using a 55 cubic foot autoclave. The method is faster than the vacuum formalin process, and pleasanter for the operator. The experiments reported here were carried out with an autoclave which was also in daily use for the high pre-vacuum steam pressure sterilization of dressings and gloves. But it would probably be undesirable to use the same autoclave routinely for both purposes because of the possibility of a mistake by the autoclave operator. It would be preferable to reserve an autoclave for low-pressure steam work only. Many hospitals nowadays have spare autoclave chambers rendered redundant by the purchase of new high pre-vacuum equipment. An old autoclave could be modified by fitting a suitable pump, condenser, pressure-controlled steam inlet valve, water ejector, temperature recorder, vacuum and pressure gauges, provided only that the chamber is sufficiently free from leaks to allow the achievement of a high vacuum.

In addition to these modifications, it would probably be advantageous to fit a wider inlet pipe and thus obtain a more rapid entry of steam into the chamber than was obtained in the experiments reported here. The failure to sterilize one pair of test organisms, described above, suggested that the safety margin should be increased. This could be done by increasing the rate of entry of steam, or by slightly prolonging the disinfection period.

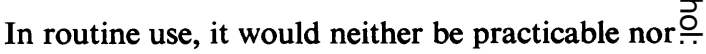
necessary to take temperature readings from the centre of the blanket load. The disinfection period $\stackrel{5}{+}$ could be timed from the moment when the temperature in the chamber drain reached $70^{\circ} \mathrm{C}$. The $\frac{\overline{\bar{N}}}{\mathrm{n}}$ adequacy of the disinfection process should be $\vec{\odot}$ checked periodically by means of control organisms. $\varrho$

The cost of modifying an existing chamber would $\omega$ depend on its capacity, which governs the size of the $\vec{\circ}$ pump. For a 25 cubic foot autoclave the cost would probably be about $£ 700$, for a 50 cubic foot auto- $\bar{\omega}$ clave, about $£ 900$. There seems no reason why an $\frac{?}{2}$ automatic control should not be fitted to a sub- $\frac{8}{0}$ atmospheric steam sterilizer. This would cost about $\vec{A}$ $£ 300$ more. If an autoclave were already fitted with ir high pre-vacuum equipment, the extra fittings for $r$ manual control of the subatmospheric steam process $\mathrm{O}$ would cost about $£ 150$.

The subatmospheric steam method should be $\overrightarrow{-}$ suitable for the disinfection of other heat-sensitive $\mathbb{\infty}$ materials besides blankets, when it is not considered ${ }_{\mathbb{\Phi}}$ necessary to destroy sporing bacteria. Wooden toys, 3 books, and eiderdown quilts have been treated without damage. It is reasonable to suppose that $\vec{\overrightarrow{ }}$ clothes and mattresses could be disinfected, but this $\odot$ has not yet been investigated.

We wish to thank Mr. J. C. Dickinson for his advice, Mr. J. Barritt for his analysis of the blankets, Mr. K. M. Henfrey for designing the autoclave fittings, and $\mathrm{Mr}$. ฏ C. L. Leitch for his advice and generous help with the $\mathbb{D}$ experiments.

We thank the Drayton Castle Company for the loan of equipment and the International Wool Secretariat for 3 defraying the cost of materials and technical assistance.

\section{REFERENCES}

Alder, V. G., and Gillespie, W. A. (1957). J. clin. Path., 10, 299. (1959). Publication D. 410, The Drayton Regulator an Instrument Co., Middlesex

Blowers, R., and Wallace, K. R. (1955). Lancet, 1, 1250.

Caplan, H. (1959). Ibid, 1, 1088.

Dickinson, J. C., Wagg, R. E., and Fairchild, G. D. (1959). British Launderers' Research Association and the International Wool Secretariat. High Temperature Laundering of Woollen Hospital Blankets, A Joint Report. British Launderers' Research Association, London.

Gillespie, W. A., and Alder, V. G. (1957). Lancet, 1, 632. 